\section{A FORTRAN IV program for profile analysis}

\author{
DAVID M. LANE \\ Rice University, Houston, Texas 77001
}

and

LAURA R. BECHTEL

Rice University, Houston, Texas 77001 and Bell Laboratories, Piscataway, New Jersey 08854

When several treatment groups are compared on a set of dependent variables, their mean response vectors can differ in overall level and/or shape. Multivariate analysis of variance, a statistical procedure employed in such situations, provides a simultaneous test of level and shape differences. Following a significant MANOVA, it is often desirable to test these possible sources of group differences separately. It is also possible for an investigator to plan a priori to test these effects separately. Procedures for testing level and shape separately are referred to as profile analysis.

The present program computes the standard univariate test for differences in level and both a univariate and multivariate test of deviations from parallelism (differences in shape) for any betweengroups design with multiple dependent variables. Also provided are univariate and multivariate tests of the hypothesis that the population means of the dependent variables are equal, the flatness hypothesis.

Limited information is available on the relative merits of univariate and multivariate techniques, although there is some literature that might help in choosing a procedure. The effect of violating assumptions is discussed by Collier, Baker, Mandeville, and Hays (1967) for the univariate case, and by Olson (1974) for the multivariate case. Davidson (1972) provides an informative discussion of factors that influence the relative power of these two techniques.

The univariate tests of the levels, parallelism, and flatness hypotheses are accomplished by analyzing the design as a mixed-model analysis of variance. These hypotheses are tested by the between-groups, groups by dependent variable, and dependent variable terms, respectively. The latter two tests require restrictive assumptions about the form of the within-groups covariance matrix. Since violating these assumptions results in an inflated Type I error rate, it is generally advisable to use a critical value of $F$ based on $\bar{\epsilon}$-corrected degrees of freedom (Winer, 1971, p. 523). The program computes $\bar{\epsilon}$ and adjusts the degrees of freedom accordingly.

The multivariate test of the parallelism hypothesis is performed by converting the original $m$ raw scores for each subject to $m-1$ measures representing the $m-1$ components of within-subjects differences, and conducting a MANOVA on the transformed scores. The same transformed scores are used in testing the flatness hypothesis: A one-sample Hotelling's $\mathrm{T}^{2}$ is used to test the null hypothesis that the population mean on each of the $m-1$ measures equals zero. The most efficient computational procedures for performing these analyses do not require that the raw scores be transformed. Instead, transformations can be performed on the hypothesis and error sums of products matrices computed as intermediate steps in MANOVA (Bock, 1975).

Input. The program requires that the error matrix (E), and the hypothesis matrix $(\mathrm{H})$ as computed in a standard MANOVA program be entered as data. Error and hypothesis matrices can be obtained by using any of a number of widely available packages, such as SPSS (Nie, Hull, Jenkins, Steinbrenner, \& Brent, 1975), SAS (Barr, Goodnight, Sall, \& Helwig, 1976), or BMD (Dixon, 1973), or from the program described by Lane and Powell (1976). If the design is a factorial MANOVA, the $\mathrm{H}$ matrix for each effect to be tested must be input. The number of subjects, the number of cells in the design, the number of dependent variables, and the degrees of freedom for the effect being tested are also required. If a test of the flatness hypothesis is requested, dependent variable means must be provided.

Output. The test of the levels hypothesis and both univariate and multivariate tests of the parallelism hypothesis are reported. The output for the univariate test of the parallelism hypothesis consists of the $F$ ratio, degrees of freedom, $\hat{\epsilon}$, and $\hat{\epsilon}$-corrected degrees of freedom. For the multivariate test, Wilk's Lambda and the Pillai-Bartlett trace statistics, as well as their respective approximate $F$ tests, are reported. ${ }^{1}$ If the flatness hypothesis is tested, the univariate result is reported as an $F$ ratio and degrees of freedom. The value of $\hat{\epsilon}$ computed to test the parallelism hypothesis is also appropriate for the flatness hypothesis. The multivariate output consists of Hotelling's $\mathrm{T}^{2}$ and its $\mathrm{F}$ test.

Computer and Language. The program is written in FORTRAN IV and was developed on an IBM 370. It should run on any system with a FORTRAN compiler. The subroutine MATINV, published by Cooley and Lohnes (1971), is used. Any matrix inversion subroutine that replaces a matrix by its inverse and computes the determinant may be substituted for MATINV.

Core and Time Requirements. The program has 222 statements and uses $27 \mathrm{~K}$ bytes in core. An additional $18 \mathrm{~K}$ bytes are used for data storage. The program executes quickly; it takes $.16 \mathrm{cpu} \mathrm{sec}$ on our system to analyze the data from a one-way design with four dependent variables.

Limitations. This program can analyze data from any 
between-groups design with multiple dependent variables. Unequal group size presents no problem as long as the $\mathrm{H}$ and $\mathrm{E}$ matrices are obtained from a program with such capabilities. At present, the program allows a maximum of 30 dependent variables. This limit can easily be increased by changing the dimension statements in the program.

Availability. A listing of the program and instructions on its use may be obtained at no cost by writing to David M. Lane, Department of Psychology, Rice University, Houston, Texas 77001.

\section{REFERENCES}

Bark, A. J., Goodnight, J. H., SAll, P. H., \& Helwig, J. T. A users guide to SAS. Raleigh: SAS Institute, 1976.

Bock, R. D. Multivariate statistical in behavioral research. New York: McGraw-Hill, 1975.

Collier, R. O., Baker, F. B., Mandeville, G. K., \& Hayes, T. F. Estimates of test size for several test procedures based on conventional variance ratios in the repeated measures design. Psychometrika, 1967, 32, 339-353.

CoOley, W. W., \& Lohnes, P. R. Multivariate data analysis. New York: Wiley, 1971.
Davidson, M. L. Univariate versus multivariate tests in repeated measures experiments. Psychological Bulletin. 1972, 77, 446-452.

Dixon, W. J. (Ed.). Biomedical computer programs. Berkeley: University of California Press, 1973.

Lane, D. M., \& Powell, R. S. N-way MANOVA: A BASIC program for minicomputers. Behavior Research Methods \& Instrumentation, 1976, 8, 382-383.

Nie, N. H., Hull, C. H., Jenkins, J. G., Steinbrenner, K., \& BRENT, D. H. Statistical package for the social sciences. New York: McGraw-Hill, 1975.

Otson, C. L. Comparative robustness of six tests in multivariate analysis of variance. Journal of the American Statistical Association, 1974, 69, 894-908.

Ouson, C. L. On choosing a test statistic in multivariate analysis of variance. Psychological Bulletin, 1976, 83, $579-586$.

WINER, B. J. Statistical principles in experimental design. New York: McGraw-Hill, 1971.

\section{NOTE}

1. The choice of test statistics was based on Olson (1976). The Pillai-Bartlett trace is the most robust to violations of assumptions. Wilk's Lambda is only slightly less robust and is frequently used.

(Received for publication September 20, 1977.) 